\title{
Antimicrobial Effect of a Peptide Containing Novel Oral Spray on Streptococcus mutans
}

\author{
Kaixin Xiong, ${ }^{1}$ Xuan Chen, ${ }^{1}$ Hantao Hu, ${ }^{1}$ Huihui Hou, ${ }^{1}$ Peng Gao, ${ }^{1}$ and Ling Zou $\mathbb{D}^{1,2}$ \\ ${ }^{1}$ State Key Laboratory of Oral Diseases, National Clinical Research Center for Oral Diseases, Sichuan University, \\ Chengdu 610041, China \\ ${ }^{2}$ State Key Laboratory of Oral Diseases, National Clinical Research Center for Oral Diseases, \\ Department of Conservation Dentistry and Endodontics, West China Hospital of Stomatology, Sichuan University, \\ Chengdu 610041, China
}

Correspondence should be addressed to Ling Zou; zouling@scu.edu.cn

Received 26 September 2019; Revised 17 January 2020; Accepted 4 February 2020; Published 11 March 2020

Academic Editor: György Schneider

Copyright (C) 2020 Kaixin Xiong et al. This is an open access article distributed under the Creative Commons Attribution License, which permits unrestricted use, distribution, and reproduction in any medium, provided the original work is properly cited.

Objective. To investigate the antibacterial effect of a novel antimicrobial peptide containing oral spray GERM CLEAN on Streptococcus mutans (S. mutans) in vitro and further explore the related mechanisms at phenotypic and transcriptional levels. Methods. The disk diffusion method was used to preliminarily appraise the antimicrobial effect of GERM CLEAN. The minimal inhibitory concentration (MIC) of GREM CLEAN towards $S$. mutans was determined by the broth dilution method. S. mutans virulence-related phenotypic assays including initial adhesive assay, $\mathrm{pH}$ drop, exopolysaccharides (EPS), and biofilm formation measurements and quantitative real-time PCR (qRT-PCR) were further applied to detect the inhibitory mechanisms of GREM CLEAN at $1 / 2 \mathrm{MIC}$. Results. The diameter $(10.18 \pm 1.744 \mathrm{~mm})$ of inhibition zones formed by GERM CLEAN preliminarily indicated its inhibitory effect on the major cariogenic bacteria $S$. mutans. The minimal inhibitory concentration of GERM CLEAN on S. mutans was $100 \%$ mass fraction (the stock solution). The study of the antibacterial mechanism showed that GERM CLEAN had a certain inhibitory effect on the initial adhesion, acid production, extracellular polysaccharides (EPS) production, and biofilm formation of $S$. mutans. GERM CLEAN disturbed $S$. mutans biofilm physiology mainly through destruction of biofilm architecture and suppression of bacterial growth. The results of qRT-PCR further confirmed that the expression levels of EPS and lactic acid generation genes including $g t f B, g t f C, g t f D$, and $l d h$ were significantly repressed by treating with GERM CLEAN, and this was consistent with our phenotypic results. Conclusion. The novel antimicrobial peptide containing oral spray GERM CLEAN has an anti-Streptococcus mutans effect and the inhibitory property may be due to suppression of the virulence factors of $S$. mutans including adhesive, acidogenicity, EPS, and biofilm formation.

\section{Introduction}

Dental caries is a prevalent chronic oral infectious disease which is featured with progressive destruction of dental hard tissue, and as one of the most prevalent infectious diseases worldwide, dental caries endangers human health throughout the life cycle and nowadays we are even suffering an elevated risk for the incidence of dental caries $[1,2]$. Vast studies on the etiology of caries reveal that multispecies microorganisms play an essential role in the occurrence and development of tooth decay, among which $S$. mutans is deemed as the main cariogenic bacteria species $[1,3-8]$. To thrive in the oral microbiota, S. mutans managed to evolve with several cariogenic characteristics including the ability to adhere to tooth surface, to survive in low $\mathrm{pH}$, and to produce acids and exopolysaccharides (EPS) $[1,9,10]$, while the conversion of diet-derived carbohydrates into EPS can further induce the formation of biofilms [11]. In recent years, using antimicrobial agents as an adjuvant for oral mechanical therapy has received much attention and has been widely used in clinical practice, but long-term use of antibiotics will cause certain toxic and side effects, resulting in flora imbalance and antibiotic resistance [12]. Thus, it is important to explore new drugs that inhibit common oral pathogenic bacteria while not necessarily lead to medical tolerance. 
To date, antibacterial peptides (AMPs) have attracted much attention as a promising alternative anti-infective for caries treatment [13-17]. AMP is a kind of small molecular polypeptide produced by the natural immune system, which widely exists in plants, insects, and mammals and has a broad-spectrum antimicrobial activity $[18,19]$. AMPs have an inhibitory effect on multiple species of bacteria, fungus, and even viruses [20-24]. Moreover, AMPs are effective against both planktonic bacteria and bacterial biofilms [25-29]. Although the specific mechanism of AMPs varies based on the amino acid composition and physicochemical properties, positively charged residues contained in most of the AMPs allow them to interact with the negatively charged bacterial membranes [30-32] and then with membrane depolarization, membrane damage, pore formation, cell lysis, peptide internalization, and intracellular targets damage $[30,31]$. These specific antimicrobial mechanisms of AMPs make them do not cause resistance easily. With the above mentioned properties, AMPs show great potential for clinical application, leading the research and medication of AMPs to raise increasing attention in fields of biopharmaceuticals [33]. However, most natural AMPs still have many disadvantages in their clinical application, including their large size, high cost and difficulty of production, and varying effective concentration against saliva dilution and degradation [34]. To improve these circumstances, taking natural AMPs as templates, many scholars have successfully designed and created many synthetic AMPs with promising antibacterial activity [35-37]. These years, Chen et al. [38] designed ZXR-2, Sullivan et al. [27] synthesized C16G2, and Zhang et al. [39] created DPS-PI, which were all synthetic AMPs that showed apparent antibacterial effect against the caries pathogenic bacteria, $S$. mutans. When compared with natural AMPs, synthetic AMPs can possess more efficient and broader-spectrum antibacterial activity and are not easy to produce resistance limitation, with lower cytotoxicity [34, 35, 40].

In recent years, many natural and synthetic AMPs have been confirmed to be inhibitory against cariogenic bacteria, defensins, Histatin 5, Human Lactoferrin [28], KSL [26], L-K6 [41], and C16G2 [42] included. And an increasing number of novel AMPs with kinds of properties are being discovered or synthesized.

GERM CLEAN is a new synthetic polypeptide. According to the manufacturer's instructions, it can effectively kill the pathogenic bacteria leading to oral mucositis, periodontitis, etc. As a novel drug product, there is no report on the antibacterial activity of GERM CLEAN on S. mutans. The aim of this study was to explore effects and the related mechanisms of GERM CLEAN on the major cariogenic bacteria, $S$. mutans, in the state of plankton and biofilm, so as to provide new perspective for the treatment of caries, as well as the experimental basis for further clinical promotion of this novel biological product.

\section{Materials and Methods}

2.1. Bacterial Strains and Growth Conditions. All chemicals and assay kits were purchased from Sigma-Aldrich (St.
Louis, MO) unless otherwise stated. S. mutans UA159 was kindly donated by Dr. Justin Merrit from the University of Oklahoma Health Sciences Center and grown in brain-heart infusion broth (BHI; Oxiod, Basingstoke, UK) anaerobically (in an atmosphere consisting of $85 \% \mathrm{~N}_{2}, 10 \% \mathrm{H}_{2}$, and $5 \%$ $\mathrm{CO}_{2}$ ) at $37^{\circ} \mathrm{C}$ [43]. Overnight cultures of UA159 were diluted 20 -fold in fresh $\mathrm{BHI}$ and grown to $\mathrm{OD}_{600 \mathrm{~nm}}=0.5$ to generate mid-exponential phase bacteria. Mid-exponential phase bacteria cultures were further 20 -fold diluted for S. mutans initial adhesion and biofilm formation using BHI medium supplemented with $1 \%$ (wt./vol) sucrose (BHIS).

2.2. The Filter Paper Disk Agar Diffusion Method. The antibacterial activity of GERM CLEAN (Shanxin, Chengdu, Sichuan, China) on S. mutans was preliminarily tested using the filter paper disc agar diffusion method introduced elsewhere with minor modification [44-47]. Briefly, $100 \mu \mathrm{l}$ of mid-exponential phase UA159 suspension was spread on fresh nutrient $\mathrm{BHI}$ agar medium plates and dried at room temperature for $5 \mathrm{~min}$. The $5 \mathrm{~mm}$ sterile filter paper disks were impregnated with GERM CLEAN (the stock solution) for $5 \mathrm{~s}$ and then were applied to the surface of above BHI bacterial culture plates. Plates were then incubated for $24 \mathrm{~h}$ at $37^{\circ} \mathrm{C}$. The antibacterial activity was evaluated by measuring the diameter of the inhibition zone.

The experiments were repeated three times independently.

\subsection{Minimal Inhibitory Concentration (MIC) Determination.}

The broth microdilution method according to the previous introduction [44, 48-50] with some modifications was applied to determine the MIC value of GERM CLEAN towards S. mutans. Two-fold serial dilutions with BHI of GERM CLEAN were prepared in 96-well microtiter plates and the final mass fractions of the tested liquor were from $100 \%$ to $0.78 \%$. First, $200 \mu \mathrm{l}$ of GERM CLEAN with a $100 \%$ mass fraction was added to the initial well. Next, $100 \mu \mathrm{L}$ of the BHI medium was added to other wells. Then, $100 \mu \mathrm{l}$ of $100 \%$ GERM CLEAN from the first well was added to the second well. After mixing, $100 \mu \mathrm{l}$ of this mixture was embedded into the following well. Similarly, the dilution procedure was continued to the 8 th well. $10 \mu \mathrm{L}$ of the $1 / 20$ th mid-exponential phase bacterial suspension with a standard concentration of $0.5\left(\mathrm{OD}_{600 \mathrm{~nm}}\right)$ was added to each well. The BHI medium was used as a negative control. The 96-well microtiter plate was then incubated for $24 \mathrm{~h}$ at $37^{\circ} \mathrm{C}$ under the anaerobic conditions mentioned above. The MIC was defined as the lowest concentration of GERM CLEAN with no visible bacteria existing and the well looked clear and transparent.

The experiments were repeated three times independently.

2.4. Growth Curve Assay. We diluted the S. mutans of midexponential phase with BHI broth to obtain the starting optical density at $600 \mathrm{~nm}$ of 0.05 . Then, we added GERM CLEAN into the 96-well microtiter plate filled with $S$. mutans culture to a final concentration of $1 / 2 \mathrm{MIC}$. BHI medium acted as a negative control. The growth of $200 \mu \mathrm{l}$ 
cultures in a 96-well microtiter plate was measured. The 96well microtiter plate was incubated at $37^{\circ} \mathrm{C}$ anaerobically $24 \mathrm{~h}$ and optical density at $600 \mathrm{~nm}$ was determined using a microplate spectrophotometer (Multiskan GO; Thermo Scientific, Waltham, MA) every hour throughout $24 \mathrm{~h}$ of incubation.

The experiment was repeated three times independently.

2.5. Initial Adhesive Assay. The initial adhesive assay was performed in 48-well microtiter plates. Mid-exponential S. mutans was diluted with BHIS as described above. Then, we added GERM CLEAN into the 48-well microtiter plates filled with $S$. mutans culture to final concentrations of $1 / 2$ MIC. BHIS medium acted as a negative control. The microtiter plates were incubated anaerobically at $37^{\circ} \mathrm{C}$ for $1 \mathrm{~h}, 2 \mathrm{~h}$, and $4 \mathrm{~h}$, respectively. After incubation, we removed the suspension and washed the wells twice with PBS to obtain the adherent cells and then added $500 \mu \mathrm{l}$ sterile BHIS broth to resuspend the adherent cells. Amount of adherent bacteria was determined by measuring optical density at $600 \mathrm{~nm}$ and the difference of $\mathrm{OD}_{600 \mathrm{~nm}}$ between treated and control groups was compared. To further evaluate the effect of GERM CLEAN at the concentration of $1 / 2 \mathrm{MIC}$ on the adherence of $S$. mutans, we calculated the antiadherence percentage.

The experiment was repeated three times independently.

The initial adherence $[51,52]: \mathrm{OD}_{600 \mathrm{~nm}}$ of assay group compared with $\mathrm{OD}_{600 \mathrm{~nm}}$ of control group.

Antiadherence percentage $[49,53]=\left(\mathrm{OD}_{600 \mathrm{~nm}}\right.$ of control group $-\mathrm{OD}_{600 \mathrm{~nm}}$ of assay group)/ $/ \mathrm{OD}_{600 \mathrm{~nm}}$ of control group $\times 100 \%$.

2.6. Biofilm Formation Assay. The effect of GERM CLEAN on S. mutans biofilm formation was explored using a quantitative crystal violet assay described elsewhere $[54,55]$ with some modifications. Briefly, mid-exponential S. mutans was diluted with BHIS broth as described above. Then, we added GERM CLEAN into the 96-well microtiter plate filled with $S$. mutans culture to final concentrations of $1 / 2 \mathrm{MIC}$. BHIS medium acted as a negative control. After anaerobic incubation $\left(24 \mathrm{~h}, 37^{\circ} \mathrm{C}\right)$, culture supernatants, and planktonic cells were removed, and the biofilm in each well was washed with PBS to remove the remaining unattached cells. The biofilms were then fixed with methanol for $15 \mathrm{~min}$ and stained with $0.1 \%$ (wt./vol) crystal violet for $15 \mathrm{~min}$, sequentially. After staining, the biofilm was rinsed twice with distilled water to remove excess $\mathrm{CV}$, and then the dye bound to the cells was resolubilized with $33 \%$ (vol/vol) glacial acetic acid for 20-30 min at room temperature. Biofilm formation was then quantified by measuring the optical density of the suspension at $600 \mathrm{~nm}$ by a microplate reader (Gene, Hong Kong, China).

The experiment was repeated three times independently.

2.7. Water-Insoluble EPS Measurement. The anthrone method $[43,56]$ was used to examine the effect of GERM CLEAN on production of water-insoluble EPS by $S$. mutans with some modifications. Briefly, biofilms were collected by sonication/vortexing in PBS buffer. Then, the precipitate was obtained by centrifugation ( $4000 \mathrm{rpm}, 10 \mathrm{~min}, 4^{\circ} \mathrm{C}$ ), washed twice with sterile water, and resuspended in $1 \mathrm{ml}$ of $0.4 \mathrm{M}$ $\mathrm{NaOH}$. Water-insoluble polysaccharides were extracted under agitation for $2 \mathrm{~h}$ at $37^{\circ} \mathrm{C}$. After centrifugation ( $4000 \mathrm{rpm}, 10 \mathrm{~min}, 4^{\circ} \mathrm{C}$ ), we added three volumes of $0.2 \%$ anthrone-sulfuric acid reagent to each supernatant sample at $95^{\circ} \mathrm{C}$ for $6 \mathrm{~min}$. The $\mathrm{OD}_{625 \mathrm{~nm}}$ was monitored with a microplate reader.

The experiment was repeated three times independently.

\subsection{Scanning Electron Microscope (SEM) Examination.} The biofilms were produced in a 24-well plate with sterilized glass slides at the bottom of wells. The biofilms were formed as described above. The specimens were rinsed with PBS three times and then fixed with $2.5 \%$ glutaraldehyde overnight at $4^{\circ} \mathrm{C}$. Following initial fixation, the specimens were washed with PBS and then serial dehydrated with ethanol (30\%, 50\%, 70\%, 80\%, 85\%, 90\%, 95\%, and $100 \%)$ for $30 \mathrm{~min}$ each time; finally, the biofilms were dried and observed at magnifications of 5,000x and 20,000 $x$ by SEM imaging (FEI, Hillsboro, USA).

\subsection{Confocal Laser Scanning Microscope (CLSM)} Examination. The biofilm specimens were formed on sterile glass coverslips put at the bottom of 24-well microtiter plates as described above. The specimens were rinsed with PBS three times and CLSM imaging was used for observation of the live/dead staining of S. mutans biofilms. Briefly, biofilms were stained using the LIVE/DEAD1 BacLight ${ }^{\mathrm{TM}}$ Bacterial Viability Kit (L-7012, Molecular Probes ${ }^{\mathrm{TM}}$, Invitrogen, Carlsbad, CA, USA) containing two component dyes (SYTO 9 and propidium iodide) following the manufacturer's instruction. The labeled biofilms were imaged with a confocal laser scanning microscope (DMIRE2, Leica, Wetzlar, Germany) equipped with a $60 \times$ oil immersion objective lens. The image channels were set according to the manufacturer. The excitation maxima for these dyes were $480 / 500 \mathrm{~nm}$ for the live cell stain SYTO 9 and $490 / 635 \mathrm{~nm}$ for the dead cell stain propidium iodide. Each biofilm was scanned at five randomly selected positions.

2.10. Glycolytic Rate Assay. The effect of GERM CLEAN on $S$. mutans glycolysis was measured by $\mathrm{pH}$ drop assay as described elsewhere with some modifications $[54,57,58]$. Briefly, S. mutans was harvested at mid-logarithmic phase $\left(10,000 \mathrm{~g}, 10 \mathrm{~min}, 4^{\circ} \mathrm{C}\right)$, washed twice with salt solution (50 $\mathrm{mM} \mathrm{KCl}+1 \mathrm{mM} \mathrm{MgCl}_{2}, \mathrm{PH}=7.2$ ), and resuspended in the same salt solution containing GERM CLEAN at the concentration of $1 / 2 \mathrm{MIC}$. Samples resuspended in BHIS served as a negative control. Glucose was added to obtain a final concentration of $1 \%$ (wt./vol) to trigger glycolysis, and the decrease in $\mathrm{pH}$ of the bacterial suspensions was evaluated over a period of $75 \mathrm{~min}$ using a glass electrode (Thermo Scientific, Waltham, MA).

The experiment was repeated three times independently. 
2.11. Quantitative Real-Time PCR ( $q R T$-PCR). QRT-PCR was used to examine the effect of GERM CLEAN on expression levels of $S$. mutans virulence trait related genes including $g t f B, g t f C$, $g t f D$, and $l d h$, and $g y r A$ was used as the internal control for quantification [56, 59-61]. Mid-exponential phase $S$. mutans was 20 -fold diluted in BHI broth, and then the bacteria culture was grown in the BHI broth with 1/2MIC level of GERM CLEAN, while BHI broth with no GERM CLEAN acted as a control.

The RNA isolation and purification procedures were conducted according to Xu et al.'s protocol [62]. RNA reverse transcription was performed with a PrimeScript ${ }^{\mathrm{TM}}$ RT reagent kit (Takara Biotechnology, Japan) to synthesize first-strand cDNAs. Specific primers for target genes were designed according to other studies $[43,56,61]$ and listed in Table 1. Each qRT-PCR reaction mixture contained SYBR ${ }^{\circledR}$ Premix Ex Taq ${ }^{\mathrm{TM}}$ II (RR820A; Takara Bio), cDNA samples $(1 \mu \mathrm{l})$, and forward and reverse gene-specific primers $(10 \mu \mathrm{M} / 1,0.5 \mu \mathrm{l}$ each). The qPCR was performed on the CFX96 Real-Time System $\left(\mathrm{C} 1000^{\mathrm{TM}}\right.$ Thermal Cycler; BioRad, Hercules, CA) applying the thermal cycling conditions described in Ming-Yun et al.'s protocol [63]. Relative expression fold changes of tested genes were calculated using the $2^{-\Delta \Delta \mathrm{Ct}}$ method, and expression level of gyrA rRNA gene was used to normalize the expression level of different genes.

The experiments were repeated three times independently.

2.12. Statistical Analysis. Differences between the experimental group and the untreated control group were compared using the $t$-test after a homogeneity test of variance with Levene's test except for evaluations of the inhibition zone and antiadherence percentage, where the Wilcoxon Signed Ranks Test was used for the former and the StudentNewman-Keuls Test was used for the latter after the aforementioned homogeneity test. Statistical analysis was performed using SPSS software (Version 20.0; IBM Corp, Armonk, USA) at a significance level of 0.05 , and then all of our figures were obtained using the Graphpad Prism7 software (version 7.00 for Windows; GraphPad Prism, Inc, La Jolla, USA) according to the analysis results.

\section{Results}

3.1. Growth Inhibition Zone Diameter Determination. The filter paper disks saturated with the stock GERM CLEAN solution could form inhibition zones on the bacterial culture plates, and diameters of the inhibition zones were $10.18 \pm 1.744 \mathrm{~mm}(>7 \mathrm{~mm}, p<0.05)$, which preliminarily indicated the antibacterial effect of GERM CLEAN on $S$. mutans.

3.2. Minimal Inhibitory Concentration (MIC) Determination. After $24 \mathrm{~h}$ incubation, the MIC value of GERM CLEAN against $S$. mutans obtained by the broth microdilution method was $100 \%$ mass fraction, which was the stock solution.
TABle 1: Specific primers of quantitative real-time PCR.

\begin{tabular}{lcc}
\hline Primers & \multicolumn{1}{c}{ Sequence } & References \\
\hline gyrA-F & $5^{\prime}$-ATTGTTGCTCGGGCTCTTCCAG-3' & {$[56,61]$} \\
gyrA-R & $5^{\prime}$-ATGCGGCTTGTCAGGAGTAACC-3' & \\
gtfB-F & $5^{\prime}$-CACTATCGGCGGTTACGAAT-3 & {$[43]$} \\
gtfB-R & $5^{\prime}$-CAATTTGGAGCAAGTCAGCA-3' & \\
gtfC-F & $5^{\prime}$-GATGCTGCAAACTTCGAACA-3' & {$[43]$} \\
gtfC-R & $5^{\prime}$-TATTGACGCTGCGTTTCTTG-3' & \\
gtfD-F & $5^{\prime}$-TTGACGGTGTTCGTGTTGAT-3' & {$[43]$} \\
gtfD-R & $5^{\prime}$-AAAGCGATAGGCGCAGTTTA-3' & \\
ldh-F & $5^{\prime}$-AAAAACCAGGCGAAACTCGC-3' & {$[43]$} \\
ldh-R & $5^{\prime}$-CTGAACGCGCATCAACATCA-3' & \\
\hline
\end{tabular}

3.3. Growth Curve Assay. We evaluated the effect of GERM CLEAN at $1 / 2 \mathrm{MIC}$ level on the basic viability of $S$. mutans by growth curve. As shown in Figure 1, the growth curves of GERM CLEAN-treated and GERM CLEAN-untreated S. mutans exhibited significant differences. It was observed that $S$. mutans treated with GERM CLEAN at 1/2MIC exhibited an extended lag phase. S. mutans of control group entered the logarithmic phase after $3 \mathrm{~h}$ and showed rapid growth till $10 \mathrm{~h}$ with a higher-end $\mathrm{OD}_{600 \mathrm{~nm}}$ of 0.8 . However, when treated with GERM CLEAN at 1/2MIC, S. mutans grew a little more slowly with the lag phase extending to $4 \mathrm{~h}$ and lower final $\mathrm{OD}_{600 \mathrm{~nm}}$ of 0.55. GERM CLEAN obviously decrease the number of final bacterial concentration, but it did not dramatically delay the progress of bacteria to logarithmic growth.

\subsection{GERM CLEAN Inhibits the Initial Adherence of S. mutans} In Vitro. The inhibition capacity of GERM CLEAN at 1/ 2MIC on $S$. mutans biofilm formation was analyzed by calculating the antiadhesion percentage. As shown in Figure 2(a), GERM CLEAN reduced S. mutans adhesion $(p<0.05)$ after $1 \mathrm{~h}, 2 \mathrm{~h}$, and $4 \mathrm{~h}$ of inoculating for biofilm formation. Figure 2(b) showed that GERM CLEAN effectively reduced the adherence of $S$. mutans in a time-dependent manner. Specifically, during the first $4 \mathrm{~h}$ after inoculation, the anti-adherence percentage increased along with the time from $6.0 \%$ at $1 \mathrm{~h}$ to $15.2 \%$ at $2 \mathrm{~h}$ and ended up with $34.1 \%$ at $4 \mathrm{~h}$.

3.5. GERM CLEAN Inhibits Water-Insoluble EPS Synthesis and Biofilm Formation of S. mutans In Vitro. GERM CLEAN at 1/2MIC level impaired $S$. mutans biofilm formation and disrupted the ability of $S$. mutans to synthesize water-insoluble EPS (Figure 3). Being treated with GERM CLEAN reduced $(p<0.05)$ up to $56.24 \%$ of biofilm formation when compared with the control group (Figure 3(a)). The waterinsoluble EPS in the treated group decreased $51.76 \%$ $(p<0.05)$ compared with the control group (Figure $3(\mathrm{~b}))$.

3.6. Scanning Electron Microscopy Examination. SEM imaging depicted the impact of GERM CLEAN on S. mutans glucan production and biofilm structure (Figure 4 ). The BHIS treated control group displayed smooth cell surface with neither apparent cell lysis nor cellular debris, while it 


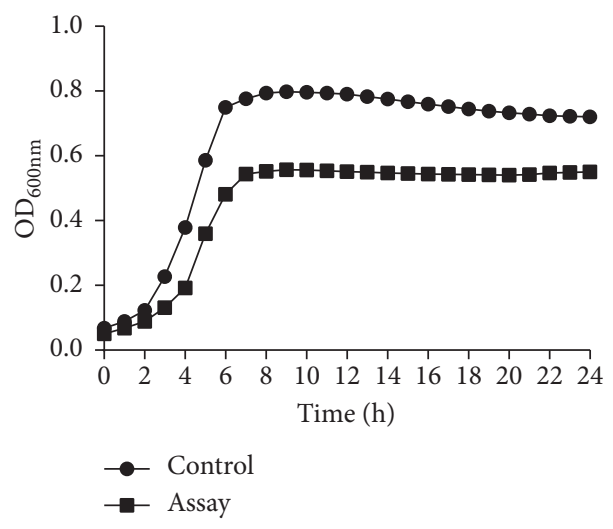

Figure 1: Effect of GERM CLEAN at 1/2MIC on the growth curve of S. mutans.

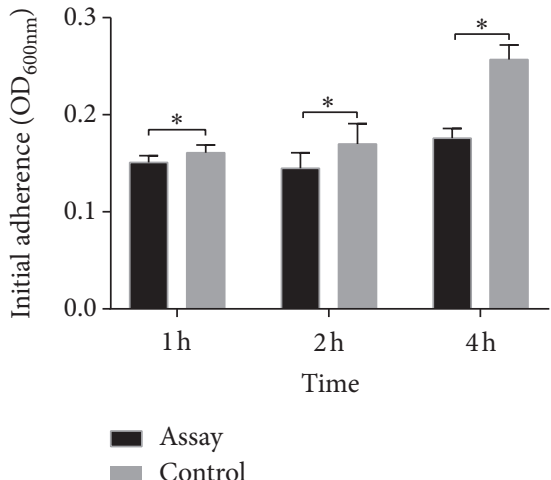

(a)

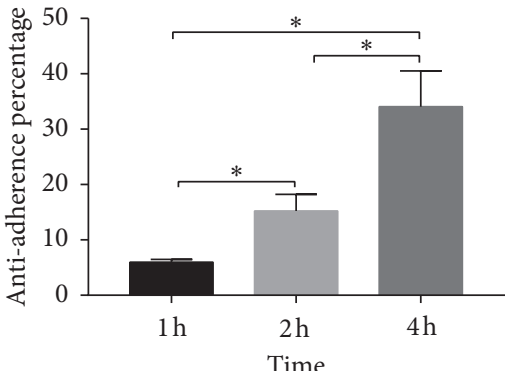

(b)

Figure 2: The anti-adherence effect of 1/2MIC GERM CLEAN on S. mutans. (a) The $\mathrm{OD}_{600 \mathrm{~nm}}$ of adherent bacteria treated with $1 / 2 \mathrm{MIC}$ level of GERM CLEAN or BHIS control; (b) the antiadherence percentage of the initial adherence stage $(1 \mathrm{~h}, 2 \mathrm{~h}$, and $4 \mathrm{~h})$ calculated by (OD600 $\mathrm{nm}$ of control group $-\mathrm{OD}_{600 \mathrm{~nm}}$ of assay group)/OD600 $\mathrm{nm}$ of control group. ${ }^{*} p<0.05$.

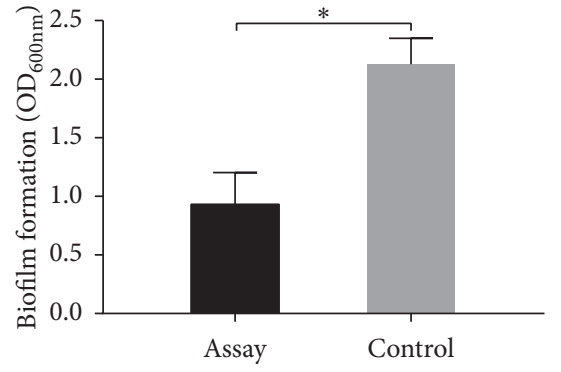

(a)

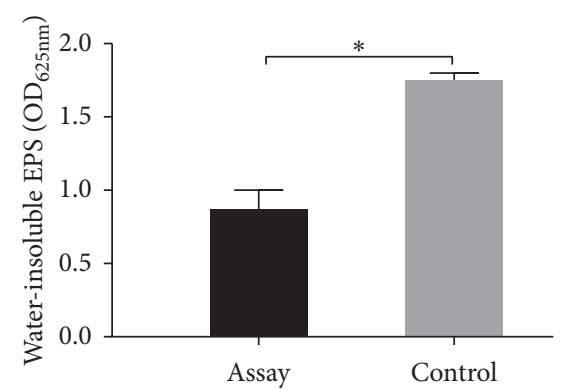

(b)

FIGURE 3: Effect of 1/2MIC GERM CLEAN on biofilm formation and water-insoluble EPS of $S$. mutans. (a) Quantitative data of the biofilm formation measured by crystal violet dye; (b) the water-insoluble EPS measured by the anthrone method. ${ }^{*} p<0.05$.

showed evident aggregation of cells with the formation of chains immersed into the EPS pool. In accordance with the results of our initial adhesion, anthrone, and biofilm quantifying assays, the GERM CLEAN-treated samples displayed rough, shrunken, distorted, and collapsed cells and obvious membrane rupture with significant dispersion of the cells, which also suggested the reduced production of EPS. And the cells in the GERM CLEAN-treated samples showed irregular shapes and obviously various sizes, with the occurrence of polarity.
3.7. Confocal Laser Scanning Microscopy (CLSM) Examination. The effect of GERM CLEAN at 1/2MIC concentration on the biofilm architecture of $S$. mutans was also analyzed by CLSM. As shown in Figure 5, GERM CLEAN showed a clear antibacterial effect that was mainly constituted of destruction of biofilms and reduction of living cells. In the control group, $S$. mutans biofilms were compact and most of the bacteria were viable. However, when treated with GERM CLEAN, S. mutans formed unconsolidated 


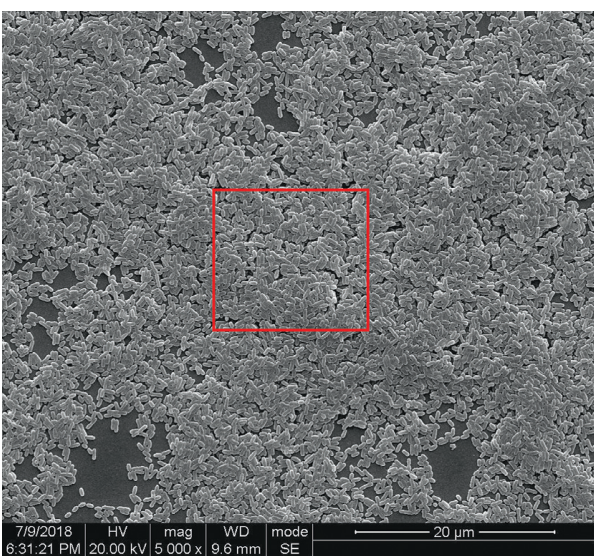

(a)

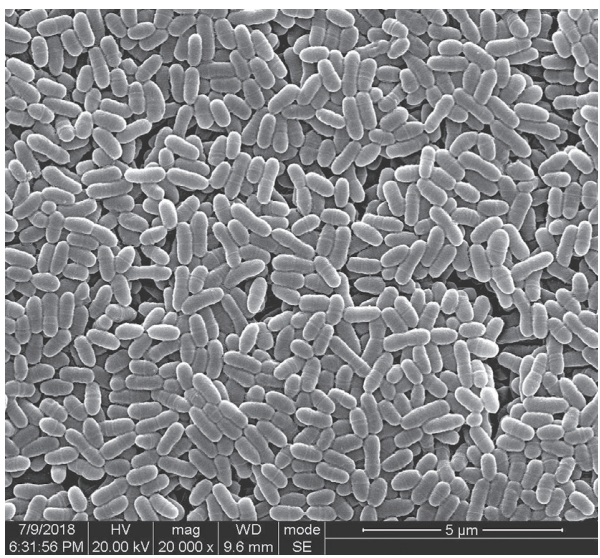

(c)

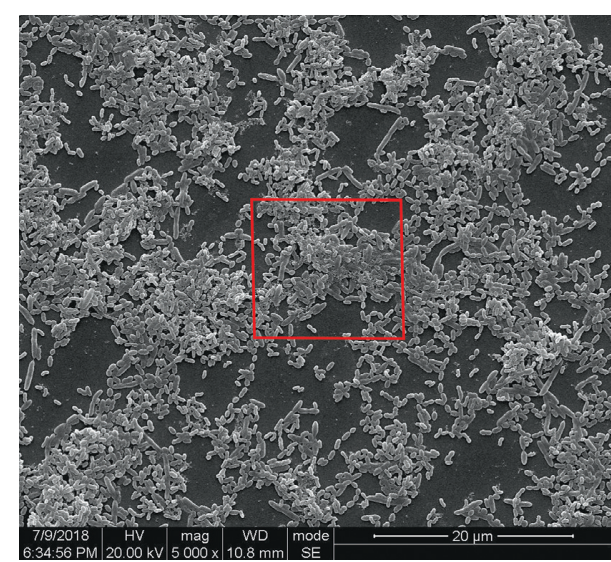

(b)

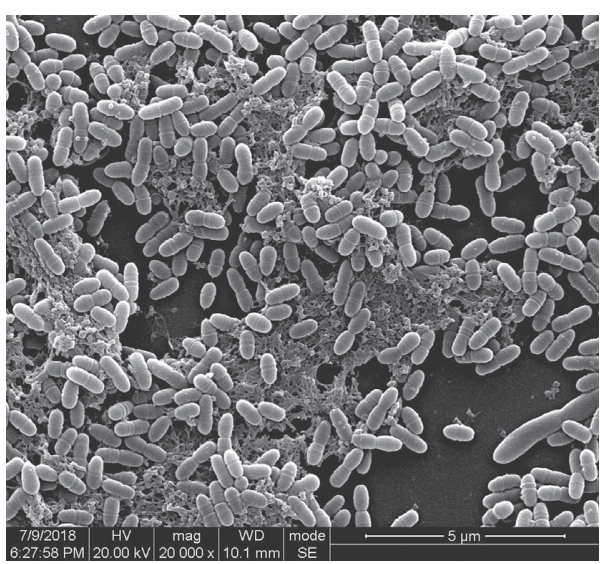

(d)

FIGURE 4: Scanning electron microscopy observation of S. mutans biofilm formed after $24 \mathrm{~h}$ of incubation. (a) and (c) were taken from the untreated control group, while (b) and (d) represented the group treated with 1/2 MIC concentration of GERM CLEAN. (a) and (b) 5000x; (c) and (d) partially magnified (20000x) from the red circles in (a) and (b), respectively.

biofilms with an apparent scattering of cells, where viable cells were diminished, while cell deaths increased.

3.8. GERM CLEAN Inhibits the Acidogenicity of S. mutans In Vitro. Results of the $\mathrm{pH}$ drop assay suggested that GERM CLEAN at the concentration of $1 / 2 \mathrm{MIC}$ level repressed S. mutans acidogenicity. As shown in Figure 6, the $\mathrm{pH}$ drop recorded in the first $15 \mathrm{~min}$ of incubation (known as initial $\mathrm{pH}$ drop) was observed maximum in both control and the GERM CLEAN-treated groups; in the control group, the $\mathrm{pH}$ of the bacterial suspension decreased quickly from 7.2 to 5.94 and then slowly ended up with 4.65 after $90 \mathrm{~min}$ of incubation, whereas the $\mathrm{pH}$ value of GREM CLEAN-treated group decreased quickly from 7.2 to 6.26 and slowly showed a higher final $\mathrm{pH}$ of $5.96(p<0.05)$.

3.9. GERM CLEAN Inhibits Expression of Virulence Genes ofS. mutans In Vitro. The expression fold changes of ldh, gtfB, $g t f C$, and $g t f D$ in S. mutans treated with GERM CLEAN at 1/ 2MIC level were shown in Figure 7. When compared with gene expressions in the control group, all those of these tested genes were downregulated after treating with GERM CLEAN $(p<0.05)$, especially for that of the $g t f B$ gene, whose expression level was decreased by nearly 100 -fold. And the expression levels of $g t f C, g t f D$, and $l d h$ were downregulated by about 20-fold, 5-fold, and 2-fold, respectively, after treated with GERM CLEAN at 1/2MIC level.

\section{Discussion}

In this study, we found that a newly marketed oral spray GERM CLEAN impaired the growth, adherence, EPS synthesis, biofilm formation, and acid production of S. mutans through in vitro $S$. mutans virulence-related phenotypic assays. Moreover, the qRT-PCR result explained that GERM CLEAN impaired virulence of $S$. mutans through downregulating expression of EPS- and acid-production related genes.

The antibacterial activity of GERM CLEAN was preliminarily verified through the antibacterial ring test, but the diameter of inhibition zones formed by GERM CLEAN was not very stable, which varied from $8.4 \mathrm{~mm}$ to $12 \mathrm{~mm}$ according to our repeated tests, and we suspected that it might be related to the variety of the peptide stability [64-69], and this hypothesis needs further confirmation. The MIC of GERM CLEAN turned out to be $100 \%$ mass fraction, which was unexpected, but on the other hand, this also indicated the mild and biocompatible properties of GERM CLEAN. 


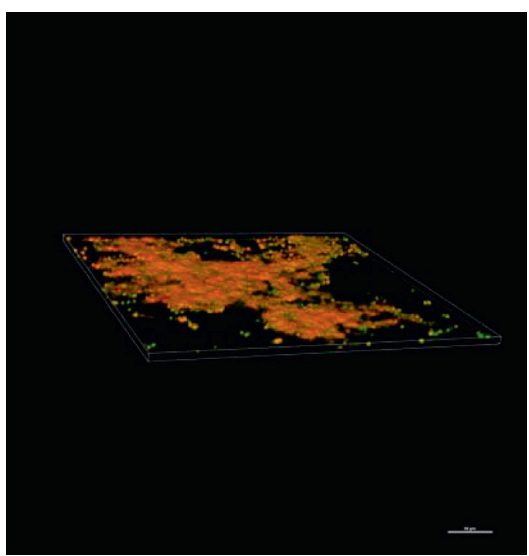

(a)

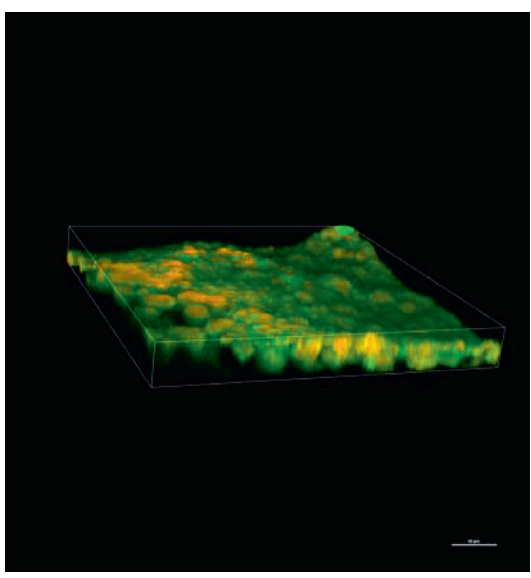

(d)

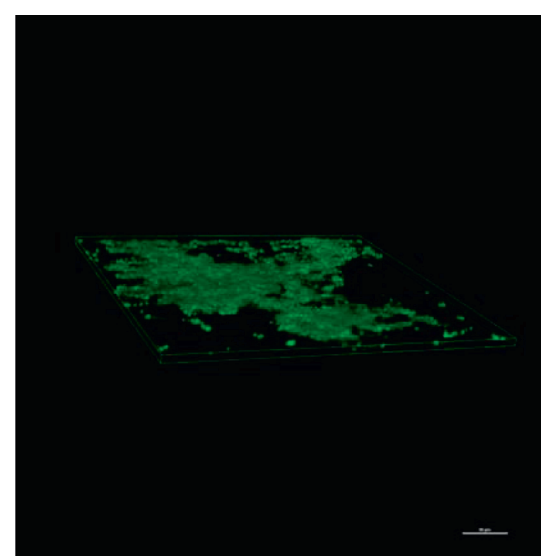

(b)

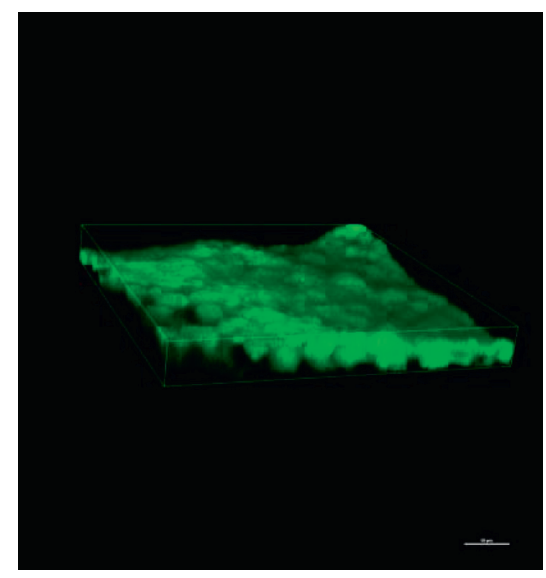

(e)

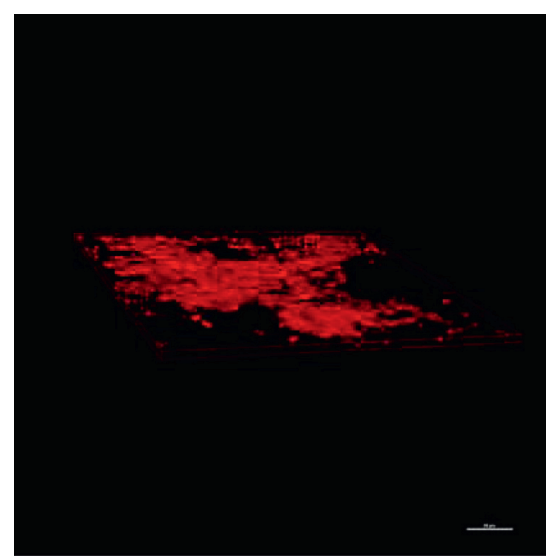

(c)

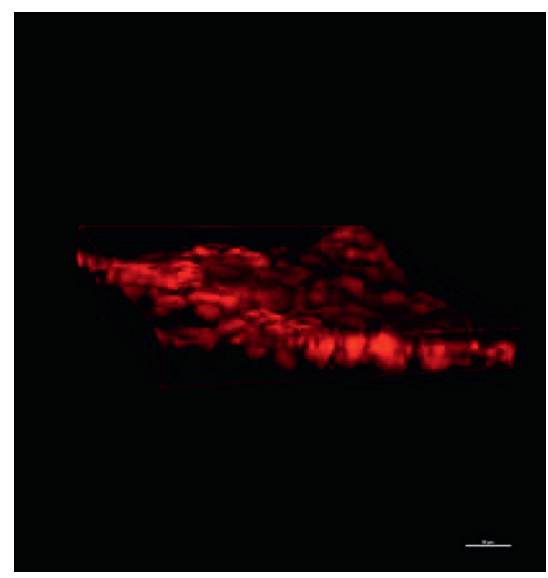

(f)

FIGURE 5: CLSM images of S. mutans biofilm formed in the presence and absence of the sub-MIC (1/2MIC) level of GERM CLEAN after $24 \mathrm{~h}$ of incubation. (a), (b), and (c) were from the treated group; (d), (e), and (f) were from the control group; (a) and (d) show the whole biofilm images; live bacteria, stained green $(b, e)$; dead cells, stained red $(c, f)$.

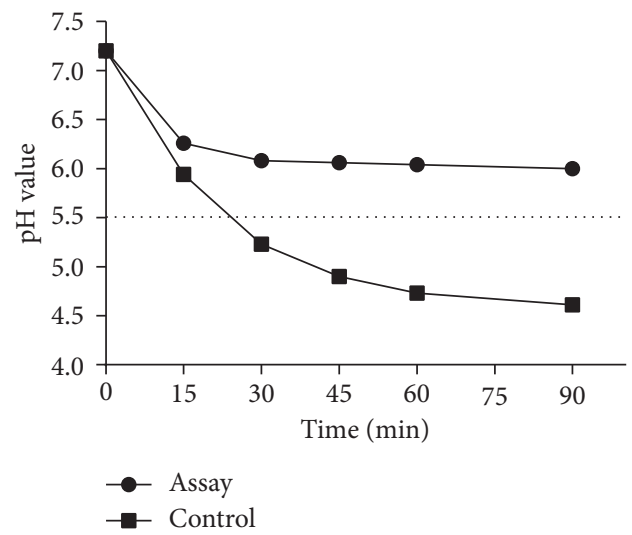

FIGURE 6: Effect of 1/2MIC concentration of GERM CLEAN on $S$. mutans acid production measured by glycolytic $\mathrm{pH}$ drop assay. The horizontal dotted line represents the critical $\mathrm{pH}$ value ( $\mathrm{pH} 5.5$ ) to $S$. mutans.

As a primary etiology of dental caries, $S$. mutans poses a strong adhesive ability to attach to the tooth surface, which is the decisive initial step in colonization, biofilm formation, and caries development [70-72]. Water-insoluble EPS in the

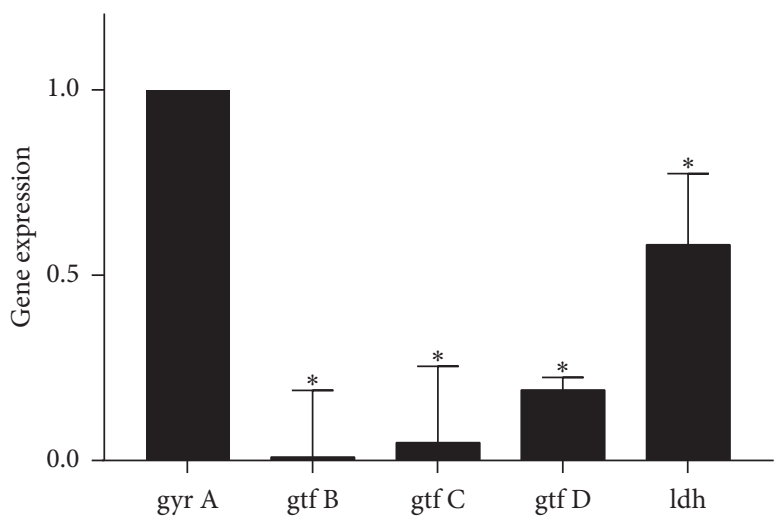

FIGURE 7: Expression of various virulence genes of $S$. mutans in response to the treatment with GERM CLEAN. Gene expression was quantified by real-time PCR, with gyrA rRNA as an internal control. ${ }^{*} p<0.05$.

matrix also plays a critical role in S. mutans carcinogenicity $[73,74]$. EPS can promote the aggregation of bacteria to form a biofilm, thus displaying cariogenic properties $[4,10,72]$. Biofilm is responsible for caries and EPS 
consolidates it, which increases the resistance of antibacterial reagents [75, 76]. Glucosyltransferases (Gtfs) secreted by $S$. mutans are the key enzymes mediating glucan synthesis, which impair the following adherence and biofilm formation. GtfB, GtfC, and GtfD are encoded by $g t f b, g t f c$, and $g t f d$ genes, respectively. GtfB makes primarily water-insoluble glucans, GtfC appears to synthesize both soluble and insoluble glucans, with water-insoluble glucans predominating, and GtfD mainly makes water-soluble glucans [77-84]. Water-insoluble glucans synthesized by GtfB and GtfC form the main scaffold of the EPS matrix and provide adhesive sites for $S$. mutans to a tooth surface as well as to other microbes [80-82]. Previous studies demonstrated that suppressed expression of $g t f B C$ genes in S. mutans could ultimately inhibit the biofilm formation because of the reduction of EPS and adherent ability [79, 83, 85-87]. Nowadays, study groups developed an increasing number of novel synthetic AMPs with confirmed antibacterial potential. Wang et al. [88] synthesized TVH19 and testified its effect on inhibiting the biofilm formation and destroying the biofilm structure of $S$. mutans. Min et al. [13] synthesized CLP-4 and demonstrated that CLP-4 could kill S. mutans cells, inhibit biofilm formation, and eradicate preformed biofilms. Jannadi et al. [89] synthesized Pep19-2.5 and Pep19-4LF and assessed that they inhibited S. mutans growth and biofilm formation. Similarly, Zhang et al. [39] designed DPS-PI, Liang et al. [90] designed LR-10, Da Silva et al. [91] designed [W7]KR12-KAEK, and all of their antibacterial activities were evaluated by assessing the inhibition of $S$. mutans growth and biofilm biomass, furthermore assessing the destruction to biofilm morphology and the damage to the bacterial surface via scanning electron microscopy. In this current study, GERM CLEAN showed capabilities on reducing the initial adherence and disrupting the biofilm formation of $S$. mutans. Results in the anthrone experiment revealed that GERM CLEAN reduced EPS synthesis, and downregulated EPS-production related gene $(g t f B, g t f C)$ expression levels further conformed the inhibition effect of GERM CLEAN on the EPS-production ability of $S$. mutans, which could mediate ineffective adhesion and biofilm formation. According to the negative effects of GERM CLEAN on S. mutans adhesion, biofilm formation, and EPS production, we speculate that GERM CLEAN could disrupt bacterial aggregation on the tooth surface and thereby the biofilm formation, thus playing a promising role in the prevention and treatment of caries. The CLSM and SEM demonstrated GERM CLEAN disrupted biofilm formation by reducing the composition of live bacteria and distorting the biofilm structure. And we speculated that it was connected with the decrease of EPS synthesis, which was verified in the anthrone assay. And the SEM showed that GERM CLEAN could cause apparent cell lysis, cellular debris, pore formation, and obvious membrane rupture, which indicated that the possible antibacterial mechanism of our AMP may be the commonly accepted electrostatic interactions.

Acid production is another noteworthy pathogenic feature of $S$. mutans. Lactate dehydrogenase $(L D H)$ encoded by $l d h$ gene is one of the most important enzymes in acid production, which acts as a key virulence of $S$. mutans, and $l d h^{-}$deficient mutant of $S$. mutans had low acidogenicity and reduced cariogenic potential [92-98]. In a previous study, Wang [43] synthesized GH12 and performed glycolysis $\mathrm{pH}$ drop assay and qRT-PCR to test its effect on acid production of $S$. mutans. With similar methods in this research, our data from the glycolysis $\mathrm{pH}$ drop assay suggested the impairment effect of GERM CLEAN on acidogenicity of S. mutans and this result was consistent with qRT-PCR data which showed that GERM CLEAN could downregulate expression of acidproduction related gene ldh. GERM CLEAN clearly repressed acid generation of $S$. mutans, implying its prevention effect on S. mutans derived tooth erosion and demineralization, which consequentially inhibits $S$. mutans carcinogenicity. On the other hand, lower final $\mathrm{pH}$ value was related to the ability of stronger acid tolerance [73] to some extent, so the higher final PH value after being treated with GERM CLEAN at $1 / 2 \mathrm{MIC}$ indicated the disruption of aciduric potential, which further impaired the cariogenic ability of $S$. mutans.

The overall effect of GERM CLEAN is evidently anticariogenic as shown by in vitro studies. All results concluded that GERM CLEAN at $1 / 2 \mathrm{MIC}$ suppressed the cariogenic pathways of $S$. mutans. But bacteriostasis on $S$. mutans of GERM CLEAN in poor stability is worth further thinking, and extraordinary comparison found that the antibacterial effect of GERM CLEAN is poorer than clinical commonly used chlorhexidine ( $\mathrm{CHX}$ ) which has a definite effect. CHX, widely used as a mouthwash, is one of the most commonly prescribed antiseptic agents in dentistry due to broadspectrum antimicrobial activity [99-101]. It adheres to tooth and mucosal surfaces and presents a high residence time and it is considered a gold standard for dental caries and periodontitis control [99, 100, 102-106]. However, CHX has some side effects which limit our common use, including tooth discoloration, impaired sense of taste, mucosal desquamation, and irritation of host tissues [103, 107-109]. What's more, CHX mouthwash needs to be gargled and its use is restricted by our environment and location. To our delight, GERM CLEAN, existing as an AMP spray which has a clear antibacterial effect, is easy to be carried. Moreover, it is mild, colorless, and tasteless, with good user experience, which overcomes the CHX's shortcomings to some degree.

So far, scholars have confirmed the antibacterial effect of many natural and synthetic AMPs, including Bac8c, Aedesin, decapeptide, XLAsp-P1, LL-37 and variant, Pep-7, and HBD3- C15 [35, 87, 110-116], which provided us with the study methods of this new AMP GERM CLEAN. What's more exciting, Wang et al. $[43,117]$ in our hospital successfully synthesized three new AMPs (GH8, GH12, and GH16) and further studied the bacteriostatic properties and mechanisms. Although reports about GERN CLEAN at home and abroad are limited before, these previous studies on other AMPs provide a classic and mature experimental scheme for the study of in vitro antibacterial effect and mechanisms of this new AMP for us.

However, we need to take the limitations of such in vitro assays into consideration. There are more than 700 species of bacteria residing on the teeth surfaces and oral soft tissues 
[102, 118]. Meanwhile, dental plaque is a multispecies biofilm $[75,102,119]$, which could cause a variety of oral diseases including dental caries, pulpitis, gingivitis, and periodontitis $[102,118,120,121]$. Therefore, in our further study, we need to examine the effect of GERM CLEAN on plaque biofilm containing multiple species of bacteria. Besides, considering the complicated bacteria-host interactions, in vivo animal models may help us observe the effect of GERM CLEAN more intuitively.

In conclusion, GERM CLEAN at $1 / 2 \mathrm{MIC}$ could reduce the acidogenicity, EPS synthesis, adherent ability, and biofilm formation of $S$. mutans through downregulating the expression levels of $g t f b, g t f c, g t f d$, and $l d h$ genes. According to the manufactures' instruction, GERM CLEAN is an orally and topically administrated anti-infectious agent, and based on the finding of our present in vitro study, we assumed that this spray could exert antibacterial effect on the main cariogenic bacteria $S$. mutans, which suggested that this product might be useful in terms of caries prevention and treatment, and it should be especially recommended to apply this novel spray to patients with a predicted high-risk of caries. However, considering the diversity and complexity of human dental plaque, further studies with animal and clinical patient trials are still needed for figuring out the best fit indications and the actual performance of GREM CLEAN in vivo.

\section{Data Availability}

The data used to support the findings of this study are available from the corresponding author upon request.

\section{Conflicts of Interest}

The authors declare that there are no conflicts of interest related to this study.

\section{Authors' Contributions}

Kaixin Xiong and Xuan Chen contributed equally to this work.

\section{Acknowledgments}

This work was supported by grants from the National Natural Science Foundation of China (Grant nos. 81570974, 31000058).

\section{References}

[1] Y. Yang, S. Liu, Y. He, Z. Chen, and M. Li, "Effect of LongZhang gargle on biofilm formation and acidogenicity of Streptococcus mutans in vitro," BioMed Research International, vol. 2016, Article ID 5829823, 8 pages, 2016.

[2] I. Strużycka, "The oral microbiome in dental caries," Polish Journal of Microbiology, vol. 63, no. 2, pp. 127-135, 2014.

[3] B. Islam, S. N. Khan, and A. U. Khan, "Dental caries: from infection to prevention," Medical Science Monitor: International Medical Journal of Experimental and Clinical Research, vol. 13, no. 11, pp. RA196-203, 2007.
[4] L. Chen, Z. Ren, X. Zhou, J. Zeng, J. Zou, and Y. Li, "Inhibition of Streptococcus mutans biofilm formation, extracellular polysaccharide production, and virulence by an oxazole derivative," Applied Microbiology and Biotechnology, vol. 100, no. 2, pp. 857-867, 2016.

[5] V. K. Kutsch, "Dental caries: an updated medical model of risk assessment," The Journal of Prosthetic Dentistry, vol. 111, no. 4, pp. 280-285, 2014.

[6] E. Hajishengallis, Y. Parsaei, M. I. Klein, and H. Koo, "Advances in the microbial etiology and pathogenesis of early childhood caries," Molecular Oral Microbiology, vol. 32, no. 1, pp. 24-34, 2017.

[7] A. P. V. Colombo and A. C. R. Tanner, "The role of bacterial biofilms in dental caries and periodontal and peri-implant diseases: a historical perspective," Journal of Dental Research, vol. 98, no. 4, pp. 373-385, 2019.

[8] V. P. Mathur and J. K. Dhillon, "Dental caries: a disease which needs attention," The Indian Journal of Pediatrics, vol. 85, no. 3, pp. 202-206, 2018.

[9] D. J. Bradshaw and R. J. M. Lynch, "Diet and the microbial aetiology of dental caries: new paradigms," International Dental Journal, vol. 63, no. S2, pp. 64-72, 2013.

[10] Z. Ren, T. Cui, J. Zeng et al., "Molecule targeting glucosyltransferase inhibits Streptococcus mutans biofilm formation and virulence," Antimicrobial Agents and Chemotherapy, vol. 60, no. 1, pp. 126-135, 2016.

[11] M. I. Klein, G. Hwang, P. H. S. Santos, O. H. Campanella, and H. Koo, "Streptococcus mutans-derived extracellular matrix in cariogenic oral biofilms," Frontiers in Cellular and Infection Microbiology, vol. 5, p. 10, 2015.

[12] B. Kouidhi, Y. M. A. Al Qurashi, and K. Chaieb, "Drug resistance of bacterial dental biofilm and the potential use of natural compounds as alternative for prevention and treatment," Microbial Pathogenesis, vol. 80, pp. 39-49, 2015.

[13] K. R. Min, A. Galvis, B. Williams, R. Rayala, P. Cudic, and D. Ajdic, "Antibacterial and antibiofilm activities of a novel synthetic cyclic lipopeptide against cariogenic Streptococcus mutans UA159," Antimicrobial Agents and Chemotherapy, vol. 61, no. 8, 2017.

[14] B. R. Da Silva, V. A. A. de Freitas, V. A. Carneiro et al., "Antimicrobial activity of the synthetic peptide Lys-a1 against oral streptococci," Peptides, vol. 42, pp. 78-83, 2013.

[15] J. Benergossi, G. Calixto, B. Fonseca-Santos et al., "Highlights in peptide nanoparticle carriers intended to oral diseases," Current Topics in Medicinal Chemistry, vol. 15, no. 4, pp. 345-355, 2015.

[16] J. Wu, S. Liu, and H. Wang, "Invasive fungi-derived defensins kill drug-resistant bacterial pathogens," Peptides, vol. 99, pp. 82-91, 2018.

[17] S. U. Gorr, "Antimicrobial peptides of the oral cavity," Periodontology 2000, vol. 51, no. 1, pp. 152-180, 2009.

[18] S. Galdiero, A. Falanga, R. Berisio, P. Grieco, G. Morelli, and M. Galdiero, "Antimicrobial peptides as an opportunity against bacterial diseases," Current Medicinal Chemistry, vol. 22, no. 14, pp. 1665-1677, 2015.

[19] J. Lakshmaiah Narayana and J.-Y. Chen, "Antimicrobial peptides: possible anti-infective agents," Peptides, vol. 72, pp. 88-94, 2015.

[20] S. S. N. Kolar, H. Baidouri, S. Hanlon, and A. M. McDermott, "Protective role of murine $\beta$-defensins 3 and 4 and cathelinrelated antimicrobial peptide in Fusarium solani keratitis," Infection and Immunity, vol. 81, no. 8, pp. 2669-2677, 2013.

[21] A. Semlali, K. P. Leung, S. Curt, and M. Rouabhia, "Antimicrobial decapeptide KSL-W attenuates Candida albicans 
virulence by modulating its effects on Toll-like receptor, human $\beta$-defensin, and cytokine expression by engineered human oral mucosa," Peptides, vol. 32, no. 5, pp. 859-867, 2011.

[22] J. M. C. Monteiro, M. D. Oliveira, R. S. Dias et al., "The antimicrobial peptide HS-1 inhibits dengue virus infection," Virology, vol. 514, pp. 79-87, 2018.

[23] E. Guaní-Guerra, T. Santos-Mendoza, S. O. Lugo-Reyes, and L. M. Terán, "Antimicrobial peptides: general overview and clinical implications in human health and disease," Clinical Immunology, vol. 135, no. 1, pp. 1-11, 2010.

[24] W. Aoki, K. Kuroda, and M. Ueda, "Next generation of antimicrobial peptides as molecular targeted medicines," Journal of Bioscience and Bioengineering, vol. 114, no. 4, pp. 365-370, 2012.

[25] N. Bionda, R. M. Fleeman, C. de la Fuente-Núñez et al., "Identification of novel cyclic lipopeptides from a positional scanning combinatorial library with enhanced antibacterial and antibiofilm activities," European Journal of Medicinal Chemistry, vol. 108, pp. 354-363, 2016.

[26] Y. Liu, L. Wang, X. Zhou, S. Hu, S. Zhang, and H. Wu, "Effect of the antimicrobial decapeptide KSL on the growth of oral pathogens and Streptococcus mutans biofilm," International Journal of Antimicrobial Agents, vol. 37, no. 1, pp. 33-38, 2011.

[27] R. Sullivan, P. Santarpia, S. Lavender et al., "Clinical efficacy of a specifically targeted antimicrobial peptide mouth rinse: targeted elimination of Streptococcus mutans and prevention of demineralization," Caries Research, vol. 45, no. 5, pp. 415-428, 2011.

[28] B. R. D. Silva, V. A. A. D. Freitas, L. G. Nascimento-Neto et al., "Antimicrobial peptide control of pathogenic microorganisms of the oral cavity: a review of the literature," Peptides, vol. 36, no. 2, pp. 315-321, 2012.

[29] G. Batoni, G. Maisetta, F. Lisa Brancatisano, S. Esin, and M. Campa, "Use of antimicrobial peptides against microbial biofilms: advantages and limits," Current Medicinal Chemistry, vol. 18, no. 2, pp. 256-279, 2011.

[30] K. A. Brogden, "Antimicrobial peptides: pore formers or metabolic inhibitors in bacteria?" Nature Reviews Microbiology, vol. 3, no. 3, pp. 238-250, 2005.

[31] F. Guilhelmelli, N. Vilela, P. Albuquerque, L. D. S. Derengowski, I. Silva-Pereira, and C. M. Kyaw, "Antibiotic development challenges: the various mechanisms of action of antimicrobial peptides and of bacterial resistance," Frontiers in Microbiology, vol. 4, p. 353, 2013.

[32] W. C. Wimley, "Describing the mechanism of antimicrobial peptide action with the interfacial activity model," ACS Chemical Biology, vol. 5, no. 10, pp. 905-917, 2010.

[33] S.-J. Kang, S. J. Park, T. Mishig-Ochir, and B.-J. Lee, “Antimicrobial peptides: therapeutic potentials," Expert Review of Anti-infective Therapy, vol. 12, no. 12, pp. 1477-1486, 2014.

[34] D. F. Christopher, A. H. Jan, E. W. H. Robert, and S. Gisbert, "Designing antimicrobial peptides: form follows function," Nature Reviews Drug Discovery, vol. 11, no. 1, pp. 37-51, 2011.

[35] P. F. Kreling, K. L. Aida, L. Massunari et al., "Cytotoxicity and the effect of cationic peptide fragments against cariogenic bacteria under planktonic and biofilm conditions," Biofouling, vol. 32, no. 9, pp. 995-1006, 2016.

[36] M. Taniguchi, A. Ochiai, K. Takahashi et al., "Antimicrobial activity and mechanism of action of a novel cationic $\alpha$-helical octadecapeptide derived from $\alpha$-amylase of rice," Biopolymers, vol. 104, no. 2, pp. 73-83, 2015.
[37] M. Zhang, W. Wei, Y. Sun et al., "Pleurocidin congeners demonstrate activity against Streptococcus and low toxicity on gingival fibroblasts," Archives of Oral Biology, vol. 70, pp. 79-87, 2016.

[38] L. Chen, L. Jia, Q. Zhang et al., "A novel antimicrobial peptide against dental-caries-associated bacteria," Anaerobe, vol. 47, pp. 165-172, 2017.

[39] L.-Y. Zhang, Z.-H. Fang, Q.-L. Li, and C. Cao, "A toothbinding antimicrobial peptide to prevent the formation of dental biofilm," Official Journal of the European Society for Biomaterials, vol. 30, no. 4, pp. 1-9, 2019.

[40] M. Zaiou, "Multifunctional antimicrobial peptides: therapeutic targets in several human diseases," Journal of Molecular Medicine, vol. 85, no. 4, pp. 317-329, 2007.

[41] D. Shang, H. Liang, S. Wei, X. Yan, Q. Yang, and Y. Sun, "Effects of antimicrobial peptide L-K6, a temporin-1CEb analog on oral pathogen growth, Streptococcus mutans biofilm formation, and anti-inflammatory activity," Applied Microbiology and Biotechnology, vol. 98, no. 20, pp. 86858695, 2014.

[42] R. Eckert, J. He, D. K. Yarbrough, F. Qi, M. H. Anderson, and W. Shi, "Targeted killing of Streptococcus mutans by a pheromone-guided "smart" antimicrobial peptide," Antimicrobial Agents and Chemotherapy, vol. 50, no. 11, pp. 3651-3657, 2006.

[43] Y. Wang, X. Wang, W. Jiang et al., "Antimicrobial peptide GH12 suppresses cariogenic virulence factors of Streptococcus mutans," Journal of Oral Microbiology, vol. 10, no. 1, 2018.

[44] B. Ghasemi, G. Sanjarani, Z. Sanjarani, and H. Majidiani, "Evaluation of anti-bacterial effects of some novel thiazole and imidazole derivatives against some pathogenic bacteria," Iranian Journal of Microbiology, vol. 7, no. 5, pp. 281-286, 2015.

[45] Y. B. Zeng, H. Wang, W. J. Zuo et al., "A fatty acid glycoside from a marine-derived fungus isolated from mangrove plant Scyphiphora hydrophyllacea," Marine Drugs, vol. 10, no. 3, pp. 598-603, 2012.

[46] S. Graham and P. J. Coote, "Potent, synergistic inhibition of Staphylococcus aureus upon exposure to a combination of the endopeptidase lysostaphin and the cationic peptide ranalexin," Journal of Antimicrobial Chemotherapy, vol. 59, no. 4, pp. 759-762, 2007.

[47] S. Voravuthikunchai, A. Lortheeranuwat, W. Jeeju, T. Sririrak, S. Phongpaichit, and T. Supawita, "Effective medicinal plants against enterohaemorrhagic Escherichia coli O157:H7," Journal of Ethnopharmacology, vol. 94, no. 1, pp. 49-54, 2004.

[48] B. Li, X. Li, H. Lin, and Y. Zhou, "Curcumin as a promising antibacterial agent: effects on metabolism and biofilm formation in," BioMed Research International, vol. 2018, Article ID 4508709, 11 pages, 2018.

[49] S. Zaleha, R. Zubaidah Haji Abdul, P. Koshy, and T. Nalina, "Antibacterial and anti-adherence effects of a plant extract mixture (PEM) and its individual constituent extracts (Psidium sp., Mangifera sp., and Mentha sp.) on single- and dual-species biofilms," PeerJ, vol. 4, no. 10, p. e2519, 2016.

[50] S. Vahabi, M. Hakemi-Vala, and S. Gholami, "In vitro antibacterial effect of hydroalcoholic extract of Lawsonia inermis, Malva sylvestris, and Boswellia serrata on aggregatibacter actinomycetemcomitans," Advanced Biomedical Research, vol. 8, no. 1, p. 22, 2019.

[51] J. Chu, T. Zhang, and K. He, "Cariogenicity features of Streptococcus mutans in presence of rubusoside.(Report)," BMC Oral Health, vol. 16, no. 1, 2016. 
[52] C. Asawahame, K. Sutjarittangtham, S. Eitssayeam, Y. Tragoolpua, B. Sirithunyalug, and J. Sirithunyalug, "Antibacterial activity and inhibition of adherence of Streptococcus mutans by propolis electrospun fibers," AAPS PharmSciTech, vol. 16, no. 1, pp. 182-191, 2015.

[53] Y. Liu, X. Zhang, Y. Wang et al., "Effect of citrus lemon oil on growth and adherence of Streptococcus mutans," World Journal of Microbiology and Biotechnology, vol. 29, no. 7, pp. 1161-1167, 2013.

[54] S. Hasan, M. Danishuddin, and A. U. Khan, "Inhibitory effect of zingiber officinale towards Streptococcus mutans virulence and caries development: in vitro and in vivo studies," BMC Microbiology, vol. 15, no. 1, p. 1, 2015.

[55] S. Hasan, K. Singh, M. Danisuddin, P. Verma, and A. Khan, "Inhibition of major virulence pathways of streptococcus mutans by quercitrin and deoxynojirimycin: a synergistic approach of infection control," PLoS One, vol. 9, no. 3, Article ID e91736, 2014.

[56] L. Lei, Y. Yang, M. Mao et al., "Modulation of biofilm exopolysaccharides by the Streptococcus mutans vicX gene," Frontiers in Microbiology, vol. 6, 2015.

[57] J. He, S. Wang, T. Wu, Y. Cao, X. Xu, and X. Zhou, "Effects of ginkgoneolic acid on the growth, acidogenicity, adherence, and biofilm of Streptococcus mutans in vitro," Folia Microbiologica, vol. 58, no. 2, pp. 147-153, 2013.

[58] J. Chen, T. Li, X. Zhou et al., "Characterization of the clustered regularly interspaced short palindromic repeats sites in Streptococcus mutans isolated from early childhood caries patients," Archives of Oral Biology, vol. 83, pp. 174180, 2017.

[59] J. He, D. Kim, X. Zhou et al., "RNA-seq reveals enhanced sugar metabolism in Co-cultured with within mixed-species biofilms," Frontiers in Microbiology, vol. 8, p. 1036, 2017.

[60] L. Zeng and R. A. Burne, "Sucrose- and fructose-specific effects on the transcriptome of Streptococcus mutans, as determined by RNA sequencing," Applied and Environmental Microbiology, vol. 82, no. 1, pp. 146-156, 2016.

[61] M.-Y. Mao, Y.-M. Yang, K.-Z. Li et al., "The rnc gene promotes exopolysaccharide synthesis and represses the vicRKX gene expressions via microRNA-Size Small RNAs in Streptococcus mutans," Frontiers in Microbiology, vol. 7, 2016.

[62] X. Xu, X. D. Zhou, and C. D. Wu, "The tea catechin epigallocatechin gallate suppresses cariogenic virulence factors of Streptococcus mutans," Antimicrobial Agents and Chemotherapy, vol. 55, no. 3, pp. 1229-1236, 2011.

[63] L. Ming-Yun, H. Rui-Jie, Z. Xue-Dong, and L. G. Richard, "Role of sortase in Streptococcus mutans under the effect of nicotine," International Journal of Oral Science, vol. 5, no. 4, pp. 206-211, 2013.

[64] B. Liu, W. Zhang, S. Gou et al., "Intramolecular cyclization of the antimicrobial peptide Polybia-MPI with triazole stapling: influence on stability and bioactivity," Journal of Peptide Science, vol. 23, no. 11, pp. 824-832, 2017.

[65] H. X. Luong, D.-H. Kim, B.-J. Lee, and Y.-W. Kim, “Antimicrobial activity and stability of stapled helices of polybiaMP1," Archives of Pharmacal Research, vol. 40, no. 12, pp. 1414-1419, 2017.

[66] N. Molchanova, P. R. Hansen, and H. Franzyk, "Advances in development of antimicrobial peptidomimetics as potential drugs," Molecules, vol. 22, no. 9, p. 1430, 2017.

[67] U. Piotrowska, E. Oledzka, A. Zgadzaj, M. Bauer, and M. Sobczak, "A novel delivery system for the controlled Release of antimicrobial peptides: citropin 1.1 and temporin A," Polymers, vol. 10, no. 5, p. 489, 2018.
[68] A. Dolle, V. B. Nagati, Y. Hunashal et al., "Disulfide engineering on temporin-SHf: stabilizing the bioactive conformation of an ultra-short antimicrobial peptide," Chemical Biology \& Drug Design, vol. 94, no. 3, pp. 1634-1646, 2019.

[69] H. Ilyas, A. Datta, and A. Bhunia, "An approach towards structure based antimicrobial peptide design for use in development of transgenic plants: a strategy for plant disease management," Current Medicinal Chemistry, vol. 24, no. 13, p. 1350, 2017.

[70] P. Kalesinskas, T. Kačergius, A. Ambrozaitis, V. Pečiulienè, and D. Ericson, "Reducing dental plaque formation and caries development. A review of current methods and implications for novel pharmaceuticals," Stomatologija, vol. 16, no. 2, pp. 44-52, 2014.

[71] E. S. Frenkel and K. Ribbeck, "Salivary mucins protect surfaces from colonization by cariogenic bacteria," Applied and Environmental Microbiology, vol. 81, no. 1, pp. 332-338, 2015.

[72] T. Larsen and N. E. Fiehn, "Dental biofilm infections-an update," APMIS, vol. 125, no. 4, pp. 376-384, 2017.

[73] S. Hasan, M. Danishuddin, M. Adil, K. Singh, P. K. Verma, and A. U. Khan, "Efficacy of E. officinalis on the cariogenic properties of Streptococcus mutans: a novel and alternative approach to suppress quorum-sensing mechanism (anticariogenic properties of E. officinalis)," PLoS One, vol. 7, no. 7, Article ID e40319, 2012.

[74] W. H. Bowen, "Dental caries-not just holes in teeth! a perspective," Molecular Oral Microbiology, vol. 31, no. 3, pp. 228-233, 2016.

[75] P. D. Marsh, "Microbiology of dental plaque biofilms and their role in oral health and caries," Dental Clinics of North America, vol. 54, no. 3, pp. 441-454, 2010.

[76] K. Zhang, S. Wang, X. Zhou et al., "Effect of antibacterial dental adhesive on multispecies biofilms formation," Journal of Dental Research, vol. 94, no. 4, pp. 622-629, 2015.

[77] L. Sadeghinejad, D. G. Cvitkovitch, W. L. Siqueira, J. P. Santerre, and Y. Finer, "Triethylene glycol up-regulates virulence-associated genes and proteins in Streptococcus mutans," PLoS One, vol. 11, no. 11, Article ID e0165760, 2016.

[78] Y. Yang, M. Mao, L. Lei et al., "Regulation of water-soluble glucan synthesis by the Streptococcus mutans dexA gene effects biofilm aggregation and cariogenic pathogenicity," Molecular Oral Microbiology, vol. 34, no. 2, pp. 51-63, 2019.

[79] T. Gong, B. Tang, X. Zhou et al., "Genome editing in Streptococcus mutans through self-targeting CRISPR arrays," Molecular Oral Microbiology, vol. 33, no. 6, pp. 440449, 2018.

[80] S. E. Cross, J. Kreth, L. Zhu et al., "Nanomechanical properties of glucans and associated cell-surface adhesion of Streptococcus mutans probed by atomic force microscopy under in situ conditions," Microbiology, vol. 153, no. 9, pp. 3124-3132, 2007.

[81] M. D. Senadheera, A. W. C. Lee, D. C. I. Hung, G. A. Spatafora, S. D. Goodman, and D. G. Cvitkovitch, "The Streptococcus mutans vicX gene product modulates gtfB/C expression, biofilm formation, genetic competence, and oxidative stress tolerance," Journal of Bacteriology, vol. 189, no. 4, pp. 1451-1458, 2007.

[82] M. D. Senadheera, B. Guggenheim, G. A. Spatafora et al., “A VicRK signal transduction system in Streptococcus mutans affects gtfBCD, gbpB, and $\mathrm{ftf}$ expression, biofilm formation, and genetic competence development," Journal of Bacteriology, vol. 187, no. 12, pp. 4064-4076, 2005.

[83] Y. Yamashita, W. H. Bowen, R. A. Burne, and H. K. Kuramitsu, "Role of the Streptococcus mutans gtf 
genes in caries induction in the specific-pathogen-free rat model," Infection and Immunity, vol. 61, no. 9, pp. 3811-3817, 1993.

[84] D. L. Wexler, M. C. Hudson, and R. A. Burne, "Streptococcus mutans fructosyltransferase (ftf) and glucosyltransferase (gtfBC) operon fusion strains in continuous culture," Infection and Immunity, vol. 61, no. 4, pp. 12591267, 1993.

[85] K. Rainey, S. M. Michalek, Z. T. Wen, and H. Wu, "Glycosyltransferase-mediated biofilm matrix dynamics and virulence of Streptococcus mutans," Applied and Environmental Microbiology, vol. 85, no. 5, 2019.

[86] Y. Yamashita, W. H. Bowen, and H. K. Kuramitsu, "Molecular analysis of a Streptococcus mutans strain exhibiting polymorphism in the tandem gtfB and gtfC genes," Infection and Immunity, vol. 60, no. 4, pp. 1618-1624, 1992.

[87] Y. Ding, W. Wang, M. Fan et al., "Antimicrobial and antibiofilm effect of Bac8c on major bacteria associated with dental caries and Streptococcus mutans biofilms," Peptides, vol. 52, pp. 61-67, 2014.

[88] X. Wang, Y. Wang, K. Wang et al., "Bifunctional anticaries peptides with antibacterial and remineralizing effects," Oral Diseases, vol. 25, no. 2, pp. 488-496, 2019.

[89] H. Jannadi, W. Correa, Z. Zhang, K. Brandenburg, R. Oueslati, and M. Rouabhia, "Antimicrobial peptides Pep19-2.5 and Pep19-4LF inhibit Streptococcus mutans growth and biofilm formation," Microbial Pathogenesis, vol. 133, Article ID 103546, 2019.

[90] D. Liang, H. Li, X. Xu, J. Liang, X. Dai, and W. Zhao, "Rational design of peptides with enhanced antimicrobial and anti-biofilm activities against cariogenic bacterium Streptococcus mutans," Chemical Biology \& Drug Design, vol. 94, no. 4, pp. 1768-1781, 2019.

[91] B. R. Da Silva, A. J. S. Conrado, A. L. Pereira et al., "Antibacterial activity of a novel antimicrobial peptide [W7] KR12-KAEK derived from KR-12 against Streptococcus mutans planktonic cells and biofilms," Biofouling, vol. 33, no. 10, pp. 835-846, 2017.

[92] R. J. Fitzgerald, B. O. Adams, H. J. Sandham, and S. Abhyankar, "Cariogenicity of a lactate dehydrogenasedeficient mutant of Streptococcus mutans serotype $\mathrm{c}$ in gnotobiotic rats," Infection and Immunity, vol. 57, no. 3, pp. 823-826, 1989.

[93] J. L. Baker, A. M. Derr, R. C. Faustoferri, and R. G. Quivey, "Loss of NADH oxidase activity in Streptococcus mutans leads to rex-mediated overcompensation in NAD+regeneration by lactate dehydrogenase," Journal of Bacteriology, vol. 197, no. 23, pp. 3645-3657, 2015.

[94] J. D. Hillman, A. Chen, and J. L. Snoep, "Genetic and physiological analysis of the lethal effect of L-(+)-lactate dehydrogenase deficiency in Streptococcus mutans: complementation by alcohol dehydrogenase from Zymomonas mobilis," Infection and Immunity, vol. 64, no. 10, pp. 4319-4323, 1996.

[95] A. Chen, J. D. Hillman, and M. Duncan, "L-(+)-lactate dehydrogenase deficiency is lethal in Streptococcus mutans," Journal of Bacteriology, vol. 176, no. 5, pp. 1542-1545, 1994.

[96] J. D. Hillman, A. Chen, M. Duncan, and S. W. Lee, "Evidence that L-(+)-lactate dehydrogenase deficiency is lethal in Streptococcus mutans," Infection and Immunity, vol. 62, no. 1, pp. 60-64, 1994.

[97] J. D. Hillman, M. J. Duncan, and K. P. Stashenko, "Cloning and expression of the gene encoding the fructose-1,6-diphosphate-dependent L-(+)-lactate dehydrogenase of
Streptococcus mutans," Infection and Immunity, vol. 58, no. 5, pp. 1290-1295, 1990.

[98] S. Abhyankar, H. J. Sandham, and K. H. Chan, "Serotype c Streptococcus mutans mutatable to lactate dehydrogenase deficiency," Journal of Dental Research, vol. 64, no. 11, pp. 1267-1271, 1985.

[99] A. C. S. Ré, M. C. Bonjovanni, M. P. Ferreira, O. Freitas, and C. P. Aires, "Effect of an experimental formulation containing chlorhexidine on pathogenic biofilms and drug release behavior in the presence or absence of bacteria," Pharmaceutics, vol. 11, no. 2, 2019.

[100] N. P. Panpaliya, P. T. Dahake, Y. J. Kale et al., "In vitro evaluation of antimicrobial property of silver nanoparticles and chlorhexidine against five different oral pathogenic bacteria," The Saudi Dental Journal, vol. 31, no. 1, pp. 76-83, 2019.

[101] B. La Combe, A.-C. Mahérault, J. Messika et al., "Oropharyngeal bacterial colonization after chlorhexidine mouthwash in mechanically ventilated critically ill patients," Anesthesiology, vol. 129, no. 6, pp. 1140-1148, 2018.

[102] Y. Zhou, S. Wang, X. Zhou et al., "Short-time antibacterial effects of dimethylaminododecyl methacrylate on oral multispecies biofilm in vitro," BioMed Research International, vol. 2019, Article ID 6393470, 10 pages, 2019.

[103] J. R. Kaspar, M. J. Godwin, I. M. Velsko, V. P. Richards, and R. A. Burne, "Spontaneously arising Streptococcus mutans variants with reduced susceptibility to chlorhexidine display genetic defects and diminished fitness," Antimicrobial Agents and Chemotherapy, vol. 63, no. 7, 2019.

[104] B. Padiyar, N. Marwah, S. Gupta, and N. Padiyar, "Comparative evaluation of effects of garlic extracts, and chlorhexidine mouthwashes on salivary counts and oral hygiene status," International Journal of Clinical Pediatric Dentistry, vol. 11, no. 4, pp. 299-306, 2018.

[105] T. Elkerbout, D. Slot, C. van Loveren, and G. Van der Weijden, "Will a chlorhexidine-fluoride mouthwash reduce plaque and gingivitis?" International Journal of Dental Hygiene, vol. 17, no. 1, pp. 3-15, 2019.

[106] D.-W. Lee, J.-E. Jung, Y.-M. Yang, J.-G. Kim, H.-K. Yi, and J.-G. Jeon, "The antibacterial activity of chlorhexidine digluconate againstStreptococcus mutansbiofilms follows sigmoidal patterns," European Journal of Oral Sciences, vol. 124, no. 5, pp. 440-446, 2016.

[107] E. Zajkani, O. Norian, F. Haghi, S. Faghihzadeh, and N. Gholami, "Comparison of the effect of $0.2 \%$ chlorhexidine and xylitol plus $920 \mathrm{ppm}$ fluoride mouthwashes on count of salivary Streptococcus mutants, a pilot study," Journal of Dentistry, vol. 19, no. 4, pp. 301-304, 2018.

[108] J. Autio-Gold, "The role of chlorhexidine in caries prevention," Operative Dentistry, vol. 33, no. 6, pp. 710-716, 2008.

[109] L. Fatemeh and S. Mahmood, "The antibacterial effect of four mouthwashes against Streptococcus mutans and Escherichia coli," Journal of Pakistan Medical Association, vol. 65, no. 4, pp. 350-353, 2015.

[110] K. B. Ahn, A. R. Kim, K.-Y. Kum, C.-H. Yun, and S. H. Han, "The synthetic human beta-defensin-3 C15 peptide exhibits antimicrobial activity against Streptococcus mutans, both alone and in combination with dental disinfectants," Journal of Microbiology, vol. 55, no. 10, pp. 830-836, 2017.

[111] S. Godreuil, N. Leban, A. Padilla et al., "Aedesin: structure and antimicrobial activity against multidrug resistant bacterial strains: e105441," PLoS One, vol. 9, no. 8, 2014.

[112] L. H. Eckhard, A. Sol, E. Abtew et al., "Biohybrid polymerantimicrobial peptide medium against Enterococcus faecalis," PLoS One, vol. 9, no. 10, 2014. 
[113] L. Yi, F. Wei, W. Lina, D. Guangyan, and W. Hongkun, "Antibacterial activity of synthetic antimicrobial decapeptide against oral bacteria," Hua Xi Kou Qiang Yi Xue Za Zhi= Huaxi Kouqiang Yixue Zazhi = West China Journal of Stomatology, vol. 32, no. 6, pp. 601-605, 2014.

[114] S. Li, L. Hao, W. Bao et al., "A novel short anionic antibacterial peptide isolated from the skin of Xenopus laevis with broad antibacterial activity and inhibitory activity against breast cancer cell," Archives of Microbiology, vol. 198, no. 5, pp. 473-482, 2016.

[115] T. Suwandecha, T. Srichana, N. Balekar, T. Nakpheng, and K. Pangsomboon, "Novel antimicrobial peptide specifically active against Porphyromonas gingivalis," Archives of Microbiology, vol. 197, no. 7, pp. 899-909, 2015.

[116] H. Yang, J. Fu, Y. Zhao, H. Shi, H. Hu, and H. Wang, "Escherichia coli PagP enzyme-based de novo design and in vitro activity of antibacterial peptide LL-37," Medical Science Monitor, vol. 23, pp. 2558-2564, 2017.

[117] Y. Wang, Y. Fan, Z. Zhou et al., "De novo synthetic short antimicrobial peptides against cariogenic bacteria," Archives of Oral Biology, vol. 80, pp. 41-50, 2017.

[118] H. Joachim, A. Aikaterini, S. Maria Eleni et al., "Mediterranean herb extracts inhibit microbial growth of representative oral microorganisms and biofilm formation of Streptococcus mutans," PLoS One, vol. 13, no. 12, Article ID e0207574, 2018.

[119] S. Filoche, L. Wong, and C. H. Sissons, "Oral biofilms: emerging concepts in microbial ecology," Journal of Dental Research, vol. 89, no. 1, pp. 8-18, 2010.

[120] S. N. Peterson, E. Snesrud, J. Liu et al., "The dental plaque microbiome in health and disease," PLoS One, vol. 8, no. 3, Article ID e58487, 2013.

[121] R. Saini, S. Saini, and S. Sharma, "Biofilm: a dental microbial infection," Journal of Natural Science, Biology and Medicine, vol. 2, no. 1, pp. 71-75, 2011. 